\title{
Nutrient intake is a predictor of lung function in obese asthmatic adolescents undergoing interdisciplinary therapy
}

\author{
Lydiane C. Rodrigues $^{1 *}$, João F. Mota ${ }^{1}$, Flávia C. Corgosinho ${ }^{1}$, Deborah C. L. Masquioº ${ }^{2}$, Ana R. Dâmaso ${ }^{2}$, \\ Sérgio Tufik ${ }^{2}$, Marco T. de Mello ${ }^{3}$, Nádia C. Cheik ${ }^{4}$ and Patrícia L. da Silva Agostinho \\ ${ }^{1}$ Federal University of Goiás, Faculty of Nutrition - FANUT/UFG, University East Sector, Goiânia 74.605-080, Brazil \\ ${ }^{2}$ Federal University of São Paulo, Graduate Program in Nutrition, São Paulo 04.020-060, Brazil \\ ${ }^{3}$ Federal University of Minas Gerais, School of Physical Education, Belo Horizonte 31.310-250, Brazil \\ ${ }^{4}$ Federal University of Uberlândia, Institute of Biomedical Sciences, Uberlândia 38.400-902, Brazil \\ ${ }^{5}$ Federal University of Goiás - Regional Jataí, School of Physical Therapy, Jatai 75.804-020, Brazil \\ (Submitted 5 June 2018 - Final revision received 28 June 2019 - Accepted 10 July 2019 - First published online 3 October 2019)
}

\section{Abstract}

Asthma-obesity is a multifactorial disease with specific asthma phenotypes that aggravate due to overweight and an unbalanced diet. Furthermore, obese asthmatic patients are corticotherapy-resistant. Therefore, the aims of the present study were to evaluate the effects of an interdisciplinary intervention on food consumption, body composition, lung function and adipokines in asthmatic and non-asthmatic obese adolescents and to investigate the influence of nutrients on lung function. Obese non-asthmatic $(n 42)$ and obese asthmatic ( $n 21)$ adolescents of both sexes were enrolled in the present study. Food intake, adipokine levels, body composition, asthma symptoms and lung function were assessed across the study. After the intervention of 1 year, there was a reduction $(P \leq 0 \cdot 01)$ in BMI, body fat percentage, visceral and subcutaneous fat and an increase $(P \leq 0 \cdot 01)$ in lean mass and all lung function variables in both groups, except the relation between forced expiratory volume in $1 \mathrm{~s}$ and forced vital capacity (FEV1:FVC) in non-asthmatic patients. Moreover, both groups decreased lipid and cholesterol consumption $(P \leq 0.01)$. The highest energy consumption $(\beta=-0.021)$ was associated with lower values of FVC. Similarly, carbohydrate consumption $(\beta=-0.06)$ and cholesterol were negative predictors $(\beta=-0.05)$ in FEV1:FVC. However, the consumption of Ca $(\beta=0.01)$, fibres $(\beta=1 \cdot 34)$ and vitamin A $(\beta=0.01)$ were positive predictors of FEV1:FVC. Asthma-obesity interdisciplinary treatment promoted an improvement on food consumption and lung function in adolescents and demonstrated that the consumption of nutrients influenced an increase in lung function.

Key words: Obesity: Asthma: Combined therapy: Food consumption: Lung function

Obesity and asthma are considered global public health problems. If no intervention is done, the prevalence worldwide is estimated to be 775 million of overweight individuals ${ }^{(1)}$ and more than 400 million of asthmatics ${ }^{(2)}$ in 2025 . There seems to be an association between the diseases ${ }^{(3)}$, and it remains a question whether asthma itself can occur first and increase the risk of obesity due to the use of corticosteroids. However, to date, there is no evidence to support this hypothesis, while there is ample evidence that obesity is a strong risk factor for asthma ${ }^{(4)}$.

Observational studies have found higher prevalence of asthma in the obese population ${ }^{(5,6)}$, and in prospective studies, the excess of visceral adiposity has been shown to be a risk factor for asthma ${ }^{(7,8)}$. Recently, the results of a meta-analysis have shown a significant relationship between overweight and asthma in children and adolescents ${ }^{(9)}$. In addition, obese nonasthmatic individuals may present impaired pulmonary function and exercise-induced bronchospasm ${ }^{(10,11)}$. These findings highlight the impact of obesity on the pathophysiology of asthma.

The present research suggests that the link between obesity and asthma occurs through two major phenotypes - (1) atopic asthma, primary, early-onset, aggravated by overweight; (2) late-onset non-atopic asthma, mainly neutrophilic inflammation - and by three routes - (1) mechanical effects of obesity, such as deeper inspirations that increase airway hyperresponsiveness; (2) inflammatory, stimulated by adipokines; (3) lifestyle and environment, such as uterine exposure, physical activity and diet ${ }^{(3,12)}$. So, asthma-obesity is a multifactorial disease with specific asthma

Abbreviations: FEV1, forced expiratory volume in $1 \mathrm{~s}$; FEV1:FVC, ratio between forced expiratory volume in $1 \mathrm{~s}$ and forced vital capacity; FVC, forced vital capacity; PEF, peak expiratory flow.

* Corresponding author: Lydiane C. Rodrigues, fax +55 6232096273, email lydianec@gmail.com 
phenotypes that aggravate due to overweight and the modern lifestyle, such as an unbalanced diet ${ }^{(12,13)}$.

Fast-food ingestion, twice or three times a week, is associated with a higher risk of severe asthma in adolescents, whereas fruit intake, with the same frequency, is related to a reduction of asthma prevalence in this population. This is possible as a fat-rich and fibre-poor diet may influence systemic inflammation of airways $^{(14)}$.

There is evidence that saturated fats contribute to higher lipopolysaccharide levels in circulation ${ }^{(15)}$, which lead to systemic endotoxaemia and toll-like 4 receptor activation, which signals the NF- $\mathrm{BB}^{(16)}$ pathway. This pathway increases the secretion of IL-17, IL-6, leptin and TNF ${ }^{(17,18)}$, which induces hyperresponsiveness of the airways ${ }^{(19)}$. On the contrary, fibre consumption can inhibit NF- $\kappa$ B activity through the metabolite butyrate, which signals the PPAR $^{(20)}$. Therefore, a diet with low levels of lipids and rich in fruit and vegetables seems to reduce inflammation and reactivity of airways ${ }^{(21)}$

Similarly, the visceral adipose tissue, through hyperplasia and hypertrophy of the adipocytes, also secretes proinflammatory substances such as C-reactive protein and leptin ${ }^{(22,23)}$, which can reach target organs such as the lung and contribute to neutrophilia ${ }^{(24)}$ and airway hyperresponsiveness ${ }^{(4)}$. However, adiponectin, an anti-inflammatory protein, seems to inhibit NF-אB pathway activation ${ }^{(20,25)}$.

In this sense, a prior study with a normo-energetic and nutrient-balanced dietary intervention improved the nutritional status and reduced asthma-related symptoms in obese asthmatic pubescent adolescents ${ }^{(26)}$. Moreover, our group ${ }^{(27)}$ previously showed that an interdisciplinary intervention with the participation of an endocrinologist, psychologists, physical education professionals, physiotherapists and registered dietitians was effective in asthma-obesity treatment, improving body composition, lung function and inflammatory biomarkers.

Asthma and asthma-obesity treatments are similar. Both aim to control the symptoms, maintain and recover lung function. However, the latest publication on asthma handling mentions that weight reduction in obese patients and a balanced diet may be effective in improving the lung function ${ }^{(2,28)}$.

Consequently, understanding the role of nutrients in asthmaobesity is important as these patients present a limited response to corticotherapy ${ }^{(29,30)}$. However, there are not enough studies investigating the effects of an interdisciplinary treatment in asthma-obesity, particularly the role of food consumption and pro- and anti-inflammatory adipokines on lung function and symptoms related to asthma. Therefore, we designed a study to evaluate the effect of an interdisciplinary intervention in food consumption, pulmonary function and adipokines of obese asthmatic patients, as well as to investigate the influence of nutrients on lung function.

\section{Methods \\ Outline and target population}

This longitudinal study was approved by the Research Ethics Committee of the Federal University of Goiás through substantiated report no. 126140/2016, as required by the Declaration of Helsinki. The inclusion criteria were postpubescent adolescents aged $15-19$ years $^{(31,32)}$, of both sexes, with BMI above the 95 th percentile of the curve referred to by the Centers for Diseases Control ${ }^{(33)}$ and not presenting any change in resting and stress electrocardiogram. The study excluded teens who participated in other nutritional intervention programmes, smoke, have musculoskeletal deformities, heart disease, or cold and flu in the last 6 weeks of the spirometric evaluation, and those who did not attend $\geq 75 \%$ of the interdisciplinary treatment programme. Then, the adolescents were divided into two groups: obese non-asthmatic (control group; $n$ 42) and obese asthmatic ( $n$ 21). All participants and legal guardians signed the free and informed consent to give the volunteers of the study the most comprehensive information about the objectives of the study, as well as the evaluations and therapies that would be submitted. Thus, the participation of adolescents in the study was voluntary and conscious.

The volunteers underwent serum biochemical evaluations, body composition and anthropometry, assessment of food consumption and lung function. The assessments were performed at the beginning and end of the interdisciplinary programme in the short and long term, 6 and 12 months, respectively, except for the biochemical tests that were evaluated after 12 months.

\section{Anthropometry and body composition}

Body mass measurements, fat and lean mass percentages were determined by Bod POD ${ }^{\circledR}$ air displacement plethysmography (version 1.69; Life Measurement Instruments; with 0.001 g precision). Body volume was measured with participants wearing minimal clothing (underpants or a tightfitting bathing suit and no jewellery) and a bathing cap while sitting quietly and breathing normally in the test chamber. Body weight was assessed using a scale attached to Bod POD with adolescents standing, bare feet, wearing as little clothing as possible. Height was measured with a stadiometer (Sanny; model ES $2030^{\circledR}$ ) with a $0 \cdot 1 \mathrm{~cm}$ precision scale. BMI was calculated as body weight divided by height squared ${ }^{(34)}$.

Subcutaneous and visceral fat measurements were performed with ATL/HDI $3000^{\circledR}$ ultrasound with a $3.5 \mathrm{MHz}$ multifrequency transducer (wideband). The stopping points to define visceral and subcutaneous fats were based according to specific standardisation. Thus, subcutaneous fat was determined by the distance between the skin and the outer face of the abdominal muscle, while the distance between the inner face of the same muscle and the anterior wall of the aortic artery was defined as visceral fat ${ }^{(35)}$.

\section{Evaluation of lung function}

For the evaluation of lung function, we used a portable spirometer (EasyOne ${ }^{\circledR} /$ model 2001). Three reproducible manoeuvres were accomplished and the best manoeuvre was subsequently chosen according the criteria of the American Thoracic Society ${ }^{(36)}$. These evaluated the forced vital capacity (FVC), which represents the largest volume of air mobilized in the lung during expiration; forced expiratory volume in $1 \mathrm{~s}$ (FEV1), which is the volume of air exhaled in 1s during FVC manoeuvre; FEV1:FVC ratio, which is the ratio of the volumes mentioned above to evaluate airway 
obstruction; and peak expiratory flow (PEF), which demonstrates the maximum air flow during FVC manoeuvre ${ }^{(37)}$. The predicted values were obtained by reference equation ${ }^{(38)}$.

Asthma diagnosis was performed by a pulmonologist, who evaluated the clinical and functional conditions of the volunteers, as recommended by the American Thoracic Society ${ }^{(36)}$. Specifically, patients with asthma should have a medical history of $\geq 6$ months of recurrent respiratory symptoms, such as cough, dyspnoea and wheezing, relieved by bronchodilator treatment, and which demonstrate impairment of functional lung conditions such as reversible airflow limitation, that is, reference values for spirometry below the predicted values for the healthy population $^{(39)}$. The questionnaire from the International Asthma and Allergies in Childhood Study (ISAAC) was used to assess asthma-related symptoms ${ }^{(40)}$.

\section{Biochemical tests}

Blood samples were collected by an in-clinic nurse through peripheral venipuncture in the forearm after a 12 -h overnight fast. After collection, the blood was centrifuged for $10 \mathrm{~min}$ at $5000 \mathrm{rpm}$ and stored at $-70^{\circ} \mathrm{C}$. The materials used for blood collection were disposable and labelled appropriately. The serum concentrations of adiponectin (Phoenix Pharmaceuticals, Belmont) and leptin (Chemicon International, Inc.) were measured by the enzyme immunoassay technique using commercial ELISA kits according to manufacturer's instructions.

\section{Assessment of food intake}

Dietary intake was assessed at baseline, after 6 and 12 months of intervention from the non-consecutive 3 - $d$ food registry, including $2 \mathrm{~d}$ of the week and $1 \mathrm{~d}$ of the weekend. Portions were reported as home measurements. The values obtained were analysed with Nutwin software (version 2.5$)^{(41)}$ based on the guidelines established by the Dietary Reference Intakes ${ }^{(42)}$.

\section{Interdisciplinary treatment}

Obese adolescents were submitted to the interdisciplinary treatment for 1 year. All obese adolescents received the same treatment, during the same period and were followed throughout the trial period by the same professionals. The interdisciplinary treatment consisted of medical, nutritional, physical and psychological therapy, and physical exercise.

From the first consultation with an endocrinologist, teens received a monthly clinical follow-up, guidance on changes in lifestyle and monitoring of clinical evolution regarding the control of obesity and its various comorbidities.

Nutritional therapy was conducted by nutritionists, composed of individual consultations, standard food plan prescription with a replacement list and group guidance sessions. Individual consultations were monthly and a hypoenergetic menu model was provided based on the recommendations proposed by sex, age and level of physical activity ${ }^{(41)}$. Thus, the menu featured a total energy value of 6276-6695 kJ and 7112-7531 kJ for female and male adolescents, respectively, and the following distribution of macronutrients: 50-60\% carbohydrates, 30\% total fats and $10-15 \%$ proteins in relation to total energy content. No dietary supplements were prescribed during therapy. Once in a week, a nutritional education session was delivered to groups with a maximum of twenty adolescents. Each session lasted $60 \mathrm{~min}$ and practical, playful and theoretical activities were developed, aimed at promoting healthy habits and nutritional education, with topics about food pyramid, food for weight loss, concepts of fat, sugars, healthy eating and eating disorders ${ }^{(43)}$.

Physical education professionals submitted adolescents to the combined exercise programme of combined exercises, three times a week, consisting of $30 \mathrm{~min}$ of aerobic exercise (exercise bike or treadmill) and another $30 \mathrm{~min}$ of resistance training per training session. All volunteers were familiar with the training protocol 2 weeks before starting the programme. Aerobic exercises were performed according to the intensity of the effort related to ventilatory threshold 1 , determined by a direct analysis of gases. The protocol was developed with a weekly change of the load, divided into heavy-load week (6-8 repetition maximum (RM)), moderate-load week (10-12 RM) and light-load week (15-20 RM). The volunteers performed eighteen sets per session, divided into three sets for each exercise. The rest interval between sets depended on the load adopted during the training session, with 2-min intervals for heavy-load week and 1-min intervals for moderate-load week $^{(44)}$.

Physical and psychological therapies were performed weekly on different days. These consisted of lessons lasting $60 \mathrm{~min}$, in groups of twenty teenagers. Physiotherapists taught classes on various topics that addressed the human body, such as notions of structures, conditions and ergonomics classes at school, at work, at home and during physical exercise. In addition, practical lessons were taught in global postural re-education groups, stretching and postural guidance ${ }^{(27)}$. Psychologists worked with self-esteem, body image, behaviour, prejudice, eating disorders and family issues to assist teens with lifestyle and quality-of-life changes ${ }^{(43)}$. All adolescents were submitted to the same programme of physical exercises and assessed for physical activity level ${ }^{(45)}$.

\section{Statistical analysis}

The sample size was based on our previous study ${ }^{(27)}$. Additionally, from our data, we calculated the effect size associated with the sample size, with $80 \%$ power and significance of $5 \%$ of the FEV1:FVC ratio between the periods, which was 1.33' (Cohen's $d$ ), and this calculation estimated that twenty volunteers would be needed, ten in each group.

The removal of outliers was performed when the peripheral value of the variables $(x)$ was: (1) $x>1.5 \times$ upper quartile + (upper quartile-lower quartile), or (2) lower quartile $x+1.5 \times$ (upper quartile-lower quartile) ${ }^{(46)}$. After removing outliers, we verified the Gaussian distribution of variables through the Shapiro-Wilk test, and the variables with normal distribution were expressed as means and standard deviations. It is noteworthy that for all the analyses, sex was controlled, that is, treated as a covariate.

The intragroup and intergroup comparison of variables with normal distribution, at baseline, 6 months and 1 year after therapy, was performed by repeated-measures of ANOVA, using paired correlation, followed by Tukey's test. Cochran's $Q$ test 
was used to analyse the proportion of symptoms related to asthma between the evaluation periods.

The Spearman test ${ }^{(47)}$ was performed for correlations, but only as an exploratory method. The backward method (Wald) for multiple regression analysis was used to determine the influence of dietary intake, body composition and adipokines on lung function in all periods. From the correlation study, we selected the variables that most correlated with the markers of lung function (FVC, FEV1, FEV1:FVC and PEF). Then for the multiple regression analysis, four models with five to eight variables were created, using $\alpha=0.05$. We found $R=0.4-0.7$ and power from 0.72 to $1 \cdot 0$.

The value of $P \leq 0.05$ was adopted for the level of statistical significance in the analyses. Regarding the pulmonary function variables, it is emphasised that the predicted values were used in all calculations.

\section{Results}

Initially, 135 volunteers were enrolled in the interdisciplinary intervention programme. However, sixty-three patients completed 12 months of intervention with $75 \%$ participation in therapies, including in physical activity, and both groups showed a significant activity level. The reasons for dropout in our study included family and financial problems, followed by internship opportunity and employment (Fig. 1).

The groups were matched according to age, sex and anthropometric variables and body composition for homogeneity $(P>0.05)$ and in order to observe only the impact of asthma. In the group of non-asthmatics obese, $76 \%$ of adolescents were female with a mean age of 16 (SD 1.5) years and height 167 (SD 0.06) cm, whereas the obese asthmatic group was composed of $67 \%$ female volunteers with a mean age of 16 (SD 1.7) years and height $167(\mathrm{SD} 0.09) \mathrm{cm}$.

\section{Effects of interdisciplinary treatment}

Both groups showed significant reduction $(P<0 \cdot 01)$ of fat, BMI, visceral and subcutaneous fat percentage. On the contrary, lean mass percentage increased after 1 year of therapy (Table 1 ). After a year of intervention, lung function variables increased $(P<0 \cdot 01)$ in both groups, except for FEV1:FVC ratio in the obese non-asthmatic group (Table 1 ). In addition, there was a reduction $(P<0.05)$ in respiratory symptoms in both groups after 12 months, with the exception of wheezing $(P=0 \cdot 183)$ in the obese non-asthmatic group. There was no improvement in adipokine concentrations in both groups.

There was a reduction in total energy intake and consumption of carbohydrates $(P<0 \cdot 01)$ after 6 months of intervention in both groups. However, between 6 months and 1 year of treatment, there was no change in the total energy intake of both groups. Carbohydrate intake was similar to the baseline in both groups after intervention. Furthermore, in the short term, there was a reduction $(P<0 \cdot 01)$ in lipids, saturated fats and cholesterol intake in both groups (Table 2 ).

The obese asthmatic group decreased $\mathrm{Mg}$ and vitamin $\mathrm{E}$ consumption $(P=0 \cdot 01)$ in the short term, but after 1 year of intervention, the intake was similar to baseline. After a year of intervention, $\mathrm{Na}$ was reduced $(P<0.05)$ in both groups. Contrarily, in both groups, the consumption of fibre, $\mathrm{Ca}, \mathrm{K}$, vitamins $\mathrm{A}$ and $\mathrm{C}$ did not change significantly (Table 3 ).

\section{Associations between diet and body composition, adipokines and lung function}

Energy consumption and nutrients were predictors of lung function parameters. The total energy value was a FVC predictor, and each $1 \mathrm{kcal}(4.184 \mathrm{~kJ})$ increase in the diet caused a 0.02 (adjusted $\beta$ ) reduction of FVC (Table 4).

Regarding macronutrients, carbohydrate consumption was inversely proportional to FEV1:FVC. Each increase of $1 \mathrm{~g}$ of carbohydrate reduced FEV1:FVC by 0.06 (adjusted $\beta$ ). Fibre intake and cholesterol were also a predictor of FEV1:FVC, and the addition of each $1 \mathrm{~g}$ of fibre in the diet contributed to an increase of 1.34 (adjusted $\beta$ ), while increasing every $1 \mathrm{mg}$ of cholesterol decreased 0.05 (adjusted $\beta$ ) of the ratio (Table 4).

Regarding micronutrients, $\mathrm{Ca}$ had a directly proportional association with FEV1:FVC, and every $1 \mathrm{mg}$ increase of $\mathrm{Ca}$ and $\mathrm{Mg}$ led to an increase of 0.01 (adjusted $\beta$ ) in FEV1:FVC. Vitamin A intake was a predictor of FEV1:FVC ratio and PEF, and each addition of $1 \mathrm{mg}$ of vitamin $\mathrm{A}$ in the diet contributed to an increase of 0.01 (adjusted $\beta$ ) of both lung markers (Table 4). After a regression analysis, no influence of adipokines and body composition on lung functions was found.

\section{Differences between obese asthmatic and non-asthmatic groups}

Obese asthmatic adolescents showed lower spirometric values $(P<0.01)$ compared with the non-asthmatic group in all periods (Table 1). Regarding anthropometric parameters and body composition, obese asthmatic had higher BMI $(P=0.02)$ only after 1 year of therapy compared with the obese non-asthmatic group. In relation to food intake, the obese asthmatic group presented a higher intake of lipids $(P=0 \cdot 04)$, polyunsaturated fats $(P=0 \cdot 01)$, cholesterol $(P=0 \cdot 01)$ (Table 2$)$ and $\operatorname{Mg}(P=0 \cdot 03)$ (Table 3$)$ in all periods. In addition, they showed higher saturated fat consumption $(P=0.02)$ (Table 2$)$ after 1 year of treatment and lower Fe intake $(P=0.01)$ at baseline (Table 3 ) compared with the obese non-asthmatic group.

\section{Discussion}

This is the first study to investigate the effect of an interdisciplinary intervention on food consumption and the relationship of nutrient consumption with adipokines and lung function in obese asthmatic adolescents. The interdisciplinary approach in asthma-obesity treatment increased lean body mass, reduced fat percentage, BMI, visceral and subcutaneous fat, besides reducing lipid, cholesterol and $\mathrm{Na}$ consumption, positively influencing the markers of lung function.

Studies indicate worse control of asthma in obese ${ }^{(48-50)}$ and improvement of symptoms due to weight loss interventions ${ }^{(4,30)}$. In the present study, there was an improvement of symptoms and pulmonary function in both groups after interdisciplinary intervention. The obese non-asthmatic group had some clinical conditions for the diagnosis of asthma but not functional conditions. 


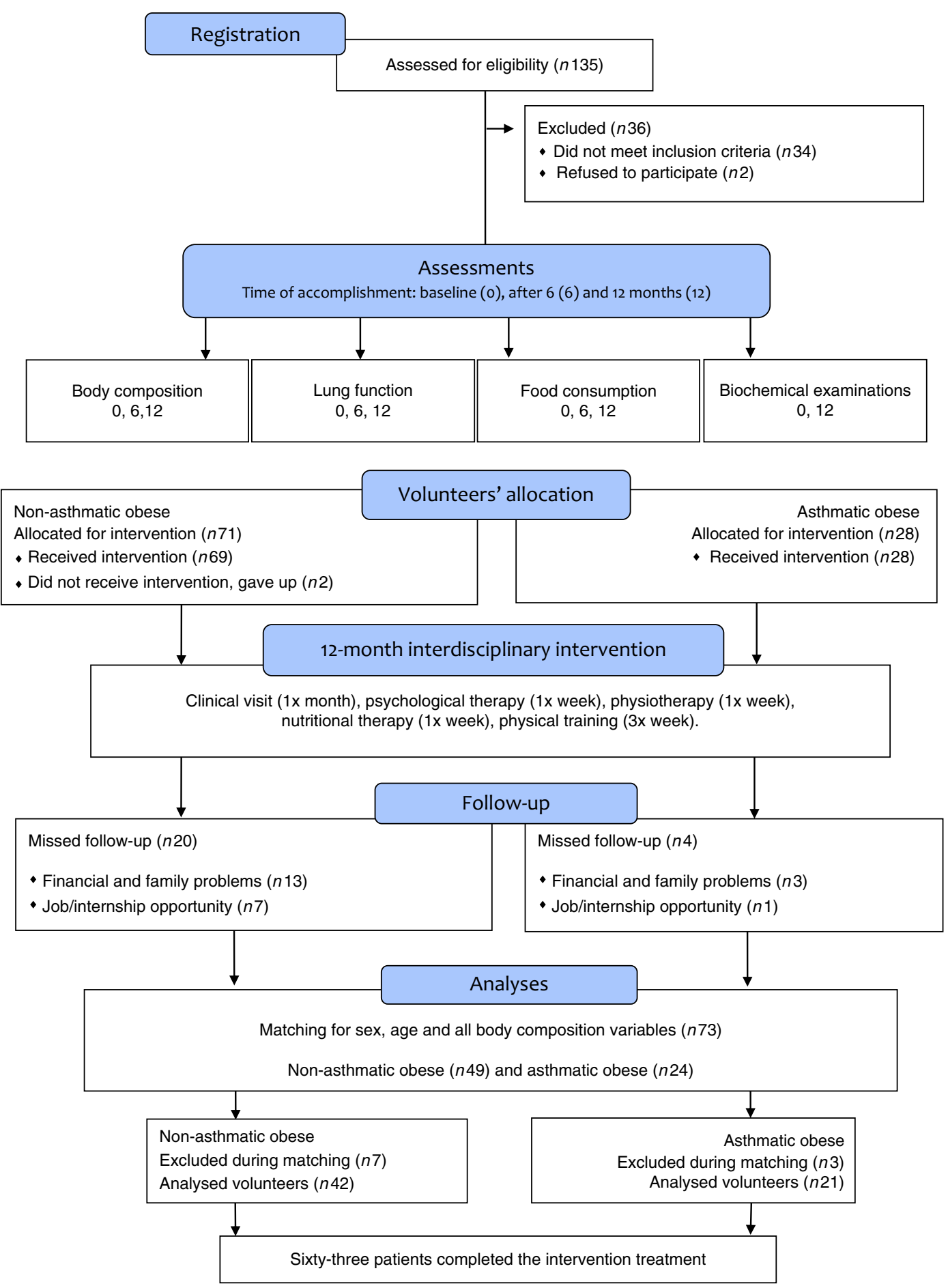

Fig. 1. Study design.

Because they underwent spirometry, they had regular airflow, so they were not asthmatics. However, the interdisciplinary intervention further improved lung function in this group.

Clinical and functional status changes of both groups were significant. Breathing is an essential process for survival, and lung function improvements can cause great benefits in the quality of life and in the performance of daily living activities. Mainly because of the increase in the FEV1:FVC ratio, values $>80 \%$ are considered normal and accompanied by reduction in asthma symptoms ${ }^{(2,40)}$. One of the mechanisms for it is the reduction of adipocytes and lower production of proinflammatory adipokines, such as leptin, which, when found in excess in the blood, are capable of reaching target organs such as the lungs and increasing inflammation of airways ${ }^{(24,25)}$.

However, we did not find differences between the groups, similar to a previous study ${ }^{(51)}$ with adolescents in which there 
Table 1. General characteristics before and after interdisciplinary therapy in obese adolescents according to asthma diagnosis (Mean values and standard deviations)

\begin{tabular}{|c|c|c|c|c|c|c|c|c|c|c|c|c|c|c|c|}
\hline \multirow[b]{3}{*}{ Variables } & \multicolumn{7}{|c|}{ Non-asthmatic ( $n$ 42) } & \multicolumn{7}{|c|}{ Asthmatic $(n 21)$} & \multirow{3}{*}{$\begin{array}{c}\text { Asthmatic } \\
\times \text { non-asthmatic } \\
P q \\
\end{array}$} \\
\hline & \multicolumn{2}{|c|}{ Baseline } & \multicolumn{2}{|c|}{6 months } & \multicolumn{2}{|c|}{1 year } & \multirow[b]{2}{*}{$P \|$} & \multicolumn{2}{|c|}{ Baseline } & \multicolumn{2}{|c|}{6 months } & \multicolumn{2}{|c|}{1 year } & \multirow[b]{2}{*}{$P \|$} & \\
\hline & Mean & SD & Mean & SD & Mean & SD & & Mean & SD & Mean & SD & Mean & SD & & \\
\hline \multicolumn{16}{|c|}{ Body composition and anthropometry } \\
\hline Body mass $(\mathrm{kg})^{\star}$ & $106.63 \dagger$ & $16 \cdot 1$ & $99 \cdot 10$ & 14.82 & $95.45 \S$ & 14.87 & 0.005 & $109 \cdot 4$ & 11.25 & 101.02 & 12.98 & $99 \cdot 33$ & 18.06 & 0.086 & 0.361 \\
\hline $\mathrm{BMI}\left(\mathrm{kg} / \mathrm{m}^{2}\right)^{\star}$ & $37.88 \dagger$ & 4.9 & 34.94 & 4.5 & $33.50 \S$ & 4.4 & $<0.001$ & 39.68 & 4.7 & 36.43 & $5 \cdot 3$ & $35.61 \S$ & $6 \cdot 8$ & 0.018 & $0.029+\dagger$ \\
\hline Body fat $(\%)^{*}$ & $48.54 \dagger$ & $4 \cdot 2$ & 43.16‡ & 4.7 & $40 \cdot 36 \S$ & $5 \cdot 7$ & $<0.001$ & $48.93 \dagger$ & $5 \cdot 1$ & $43 \cdot 35 \ddagger$ & $6 \cdot 3$ & $41 \cdot 24 \S$ & $7 \cdot 2$ & $<0.001$ & 0.341 \\
\hline Lean mass $(\%)^{\star}$ & $51.73 \dagger$ & 3.9 & $56.92 \ddagger$ & 4.7 & $59.64 \S$ & $5 \cdot 7$ & $<0.001$ & $51.07 \dagger$ & $5 \cdot 1$ & $56 \cdot 69 \ddagger$ & $6 \cdot 2$ & $58.75 \S$ & $7 \cdot 2$ & $<0.001$ & 0.334 \\
\hline Visceral fat $(\mathrm{cm})^{*}$ & $4.49 \dagger$ & 1.0 & 3.26 & 1.0 & $2.67 \S$ & 1.0 & $<0.001$ & $4.16 \dagger$ & 1.0 & 3.34 & 0.9 & $2.62 \S$ & 1.1 & $<0.001$ & 0.992 \\
\hline Subcutaneous fat $(\mathrm{cm})^{*}$ & $4 \cdot 10 \dagger$ & 0.6 & $3 \cdot 31$ & 0.3 & $3 \cdot 31 \S$ & 0.5 & $<0.001$ & $3.98 \dagger$ & 0.5 & $3 \cdot 30$ & 0.5 & $3 \cdot 12 \S$ & 0.7 & $<0.001$ & 0.496 \\
\hline \multicolumn{16}{|l|}{ Lung function } \\
\hline FVC (\% predicted) & $95.43 \dagger$ & 8.2 & $102 \cdot 76 \ddagger$ & 11.15 & $113 \cdot 17 \S$ & 12.53 & $<0.001$ & $88.66+$ & $7 \cdot 3$ & $96.73 \ddagger$ & 7.4 & $109 \cdot 15 \S$ & 11.4 & $<0.001$ & $<0.001$ 执 \\
\hline FEV1 (\% predicted) & $87.55 \dagger$ & 5.9 & $97.92 \ddagger$ & $8 \cdot 3$ & $109 \cdot 36 \S$ & $12 \cdot 3$ & $<0.001$ & 77.05 & 6.5 & $84.57 \ddagger$ & 3.4 & $95.11 \S$ & $11 \cdot 0$ & $<0.001$ & $<0.001 \neq \ddagger$ \\
\hline FEV1:FVC (\% predicted) & 95.39 & $8 \cdot 1$ & 99.60 & $5 \cdot 1$ & 96.75 & 7.9 & 0.131 & $76 \cdot 26 \dagger$ & 9.5 & $85 \cdot 13 \ddagger$ & $5 \cdot 7$ & $93.84 \S$ & 6.9 & $<0.001$ & $<0.001 \neq \ddagger$ \\
\hline $\begin{array}{l}\text { PEF (\% predicted) } \\
\text { Adipokines }\end{array}$ & $86 \cdot 10 \dagger$ & $10 \cdot 2$ & $100 \cdot 82 \ddagger$ & $11 \cdot 4$ & $103 \cdot 80 \S$ & $10 \cdot 8$ & $<0.001$ & $76 \cdot 84 \dagger$ & $4 \cdot 3$ & $86 \cdot 20 \ddagger$ & 4.6 & $95 \cdot 80 \S$ & $10 \cdot 0$ & $<0.001$ & $<0.001 \neq \ddagger$ \\
\hline Adiponectin (ng/ml) & $6 \cdot 81$ & 3.9 & - & - & 8.53 & $5 \cdot 4$ & 0.109 & 5.73 & $3 \cdot 0$ & - & - & $7 \cdot 30$ & 4.6 & 0.266 & 0.259 \\
\hline Leptin $(\mathrm{ng} / \mathrm{ml})$ & $34 \cdot 74$ & $15 \cdot 3$ & - & - & $24 \cdot 36$ & $13 \cdot 0$ & 0.999 & 29.91 & $11 \cdot 6$ & - & - & $23 \cdot 30$ & 9.6 & 0.291 & 0.060 \\
\hline \multicolumn{16}{|l|}{ Symptoms (\%) } \\
\hline Asthma-related symptoms & $20 \dagger$ & & 11 & & $12 \S$ & & 0.038 & $52 \dagger$ & & 33 & & $23 \S$ & & 0.030 & $0.017^{\star \star}$ \\
\hline Cough & $20 \dagger$ & & 10 & & $12 \S$ & & 0.040 & $52 \dagger$ & & 25 & & $15 \S$ & & 0.046 & $0.017^{\star *}$ \\
\hline Wheeze & 5 & & 2 & & 0 & & 0.183 & $48 \dagger$ & & 9 & & $8 \S$ & & 0.015 & $<0.001^{\star *}$ \\
\hline
\end{tabular}


Table 2. Macronutrient consumption before and after interdisciplinary therapy in obese adolescents according to asthma diagnosis (Mean values and standard deviations)

\begin{tabular}{|c|c|c|c|c|c|c|c|c|c|c|c|c|c|c|c|}
\hline \multirow[b]{3}{*}{ Variables } & \multicolumn{7}{|c|}{ Non-asthmatic ( $n$ 42) } & \multicolumn{7}{|c|}{ Asthmatic ( $n 21)$} & \multirow{3}{*}{$\begin{array}{c}\text { Asthmatic } \\
\times \text { non-asthmatic } \\
P \|\end{array}$} \\
\hline & \multicolumn{2}{|c|}{ Baseline } & \multicolumn{2}{|c|}{6 months } & \multicolumn{2}{|c|}{1 year } & \multirow[b]{2}{*}{$P \S$} & \multicolumn{2}{|c|}{ Baseline } & \multicolumn{2}{|c|}{6 months } & \multicolumn{2}{|c|}{1 year } & \multirow[b]{2}{*}{$P \S$} & \\
\hline & Mean & SD & Mean & SD & Mean & SD & & Mean & SD & Mean & SD & Mean & SD & & \\
\hline Total energy (kJ) & $6109 \cdot 93^{*}$ & $1680 \cdot 2$ & $4745 \cdot 86$ & $994 \cdot 1$ & $5182 \cdot 80 \ddagger$ & 1207.5 & $<0.001$ & $7437.98^{\star}$ & $1870 \cdot 2$ & 5286.52 & $1206 \cdot 6$ & $5359.95 \ddagger$ & $1212 \cdot 9$ & $<0.001$ & 0.078 \\
\hline Carbohydrates (g) & $183 \cdot 28^{*}$ & 50.9 & $162 \cdot 11 \dagger$ & 0445.9 & 172.32 & 38.4 & 0.026 & $208 \cdot 71^{*}$ & $64 \cdot 1$ & $163.59 \dagger$ & 29.7 & 184.07 & $36 \cdot 8$ & 0.016 & 0.154 \\
\hline Carbohydrates (\%) & $53.46^{*}$ & 6.9 & $56 \cdot 42$ & 8.1 & $57.45 \ddagger$ & 7.4 & 0.036 & 52.01 & $6 \cdot 1$ & 54.90 & $5 \cdot 0$ & 54.96 & 4.6 & 0.159 & 0.509 \\
\hline Proteins (g) & $74.65^{*}$ & $25 \cdot 1$ & $60 \cdot 79$ & 11.5 & $61.26 \ddagger$ & $21 \cdot 1$ & 0.018 & $94.34^{*}$ & 33.0 & 60.14 & $16 \cdot 1$ & $62 \cdot 41 \ddagger$ & 18.4 & $<0.001$ & 0.480 \\
\hline Proteins (\%) & $18 \cdot 77$ & 4.4 & $20 \cdot 48$ & 3.6 & 19.78 & 4.5 & 0.187 & 18.91 & 3.8 & 18.90 & 4.5 & $18 \cdot 72$ & 3.8 & 0.989 & 0.121 \\
\hline Lipids (g) & $51.92^{*}$ & $22 \cdot 2$ & 33.81 & $14 \cdot 2$ & $29 \cdot 28 \ddagger$ & 7.9 & $<0.001$ & $58 \cdot 83^{\star}$ & $15 \cdot 9$ & $40 \cdot 12$ & $12 \cdot 7$ & $35 \cdot 36 \neq$ & $12 \cdot 6$ & $<0.001$ & $0.043^{\star \star}$ \\
\hline Lipids (\%) & $28.88^{*}$ & $6 \cdot 1$ & 24.49 & 6.0 & $22.00 \ddagger$ & 4.7 & 0.001 & $31.09^{*}$ & 5.3 & 25.68 & 5.3 & $24.08 \ddagger$ & 4.7 & $<0.001$ & 0.089 \\
\hline Saturated fats (g) & $15 \cdot 65^{\star}$ & $7 \cdot 7$ & 8.89 & 4.9 & $7.70 \ddagger$ & 3.0 & $<0.001$ & $17 \cdot 33^{*}$ & 7.3 & $9.52 \dagger$ & 4.0 & $10.53 \ddagger$ & 4.6 & $<0.001$ & 0.0270 \\
\hline Saturated fats (\%) & $8.03^{*}$ & $2 \cdot 8$ & $6 \cdot 61$ & $3 \cdot 2$ & $5.97 \ddagger$ & $2 \cdot 0$ & 0.016 & 8.99 & $2 \cdot 8$ & 6.51 & 2.6 & $7 \cdot 29$ & $2 \cdot 8$ & 0.086 & 0.867 \\
\hline Monounsaturated fats (g) & $12 \cdot 99^{*}$ & 7.6 & 8.49 & 4.2 & $7.82 \ddagger$ & 2.5 & 0.001 & $12 \cdot 73^{*}$ & 5.1 & 10.38 & $5 \cdot 1$ & $9.53 \ddagger$ & 3.9 & $<0.001$ & 0.116 \\
\hline Monounsaturated fats (\%) & $7 \cdot 13$ & 3.4 & 6.72 & $2 \cdot 7$ & $5 \cdot 25 \ddagger$ & 1.7 & 0.022 & 6.68 & 4.3 & 7.00 & 2.5 & 6.53 & $2 \cdot 1$ & 0.741 & 0.651 \\
\hline Polyunsaturated fats (g) & 4.91 & $2 \cdot 3$ & 4.26 & 2.8 & $3.08 \ddagger$ & 0.9 & 0.007 & 7.01 & $2 \cdot 7$ & $6 \cdot 20$ & $2 \cdot 8$ & $5.06 \ddagger$ & $2 \cdot 6$ & 0.009 & $0.018 \eta$ \\
\hline Polyunsaturated fats (\%) & 2.88 & 1.6 & $2 \cdot 11$ & 1.3 & 2.42 & 0.8 & 0.094 & $2 \cdot 29$ & $2 \cdot 1$ & 1.65 & 1.9 & 3.12 & 1.3 & 0.274 & 0.688 \\
\hline Cholesterol (mg) & $205.43^{*}$ & 83.0 & 114.85 & 49.0 & $123 \cdot 74 \ddagger$ & $54 \cdot 3$ & $<0.001$ & $265.88^{*}$ & 87.8 & $168 \cdot 24$ & $65 \cdot 8$ & $141.45 \ddagger$ & $52 \cdot 6$ & $<0.001$ & $0.017 \rrbracket$ \\
\hline
\end{tabular}

* Significant intragroup change baseline $v .6$ months $(P<0.05)$

† Significant intragroup change $6 v .12$ months $(P<0.05)$.

¥ Significant intragroup change baseline $v$. 12 months $(P<0.05)$.

$\S$ Interdisciplinary therapy effect (ANOVA and Tukey post hoc).

II Difference only after 1 year of intervention.

** Difference only after 1 year of intervention.
${ }^{*}$ Difference in all periods $(P \leq 0.05$; ANOVA and Tukey post hoc). 
Table 4. Multiple regression analysis for baseline lung function determinants* ( $\beta$ Coefficients and $P$ values)

\begin{tabular}{llrr}
\hline & \multicolumn{3}{c}{ Non-asthmatic + asthmatic $(n$ 63) } \\
\cline { 2 - 4 } Consumption variables & Lung function $(\%)$ & \multicolumn{1}{c}{$\beta$} & \multicolumn{1}{c}{$P$} \\
\hline Total energy (kJ) & FVC & -0.021 & 0.022 \\
Carbohydrates $(\mathrm{g})$ & FEV1:FVC & -0.064 & 0.023 \\
Fibres $(\mathrm{g})$ & FEV1:FVC & 1.349 & $<0.001$ \\
Cholesterol (mg) & FEV1:FVC & -0.050 & 0.020 \\
Ca (mg) & FEV1:FVC & 0.018 & 0.018 \\
Vitamin A (mg) & FEV1:FVC & 0.013 & 0.034 \\
& PEF & 0.017 & 0.032
\end{tabular}

$\mathrm{FVC}$, forced vital capacity; FEV1:FVC, ratio between respiratory volume in $1 \mathrm{~s}$ and FVC; PEF, peak expiratory flow.

${ }^{*} P \leq 0.05$; variables controlled by adipokines, BMI, body fat, lipids, saturated fats. Model 1, FVC (\%): BMI, total energy, lipids, cholesterol, saturated fats. Model 2, FEV1 (\%): leptin, adiponectin, BMI, cholesterol, fibres, vitamin A. Model 3, PEF (\%): body fat, carbohydrates, fibres, cholesterol, $\mathrm{Ca}$, vitamin A, saturated fats. Model 4, FEV1:FVC (\%): body fat, carbohydrates, fibres, leptin, cholesterol, Ca, vitamin A, leptin.

was no difference in serum concentrations of adiponectin and leptin in obese non-asthmatic and asthmatic groups. In addition, in the present study, improvement in lung function was independent of systemic inflammation, since there was no difference in adipokine concentrations after the intervention. These findings corroborate a randomised clinical trial with children and adolescents between 8 and 17 years of age who displayed a reduction in BMI after a low-energy diet followed by lung function improvement without alteration in inflammatory markers ${ }^{(52)}$. In a similar study, leptin of obese adolescents also did not present a significant change after intervention ${ }^{(53)}$.

These results differ from a previous study conducted by our group $^{(27)}$, which showed that an interdisciplinary intervention reduced serum leptin concentrations and increased adiponectin in obese adolescents, regardless of asthma diagnosis. However, obese adolescents had higher concentrations of leptin and adiponectin at the beginning of treatment compared with the present study.

In a separate sex re-analysis, we found that at baseline the mean leptin concentration was similar in both groups and sexes (obese asthmatic boys: 16.0 (SD 3.76) ng/ml; obese asthmatic girls: $16 \cdot 65$ (sD 6.6) ng/ml; obese non-asthmatic boys: 16.45 (sD 1.76) ng/ml; obese non-asthmatic girls: $19 \cdot 47$ (SD 16.38) ng/ml). Obese nonasthmatic girls showed greater dispersion in leptin concentrations. The mean leptin levels were normal compared with the reference values for healthy adolescents, regarding sex and age ${ }^{(54)}$.

Thus, we believe that serum adipokine concentrations in the present study were not problematic, as these were below the values obtained in other studies with obese adolescents ${ }^{(27,53)}$. In addition, the fact that adipokine concentrations remain similar after interdisciplinary intervention suggests that other factors, besides fat percentage and $\mathrm{BMI}^{(53,55,56)}$, may be involved in the expression of adiponectin and leptin, such as sexual maturation ${ }^{(57)}$.

In a cohort, an increase in androgen levels during puberty was negatively correlated with blood adiponectin concentrations in both sexes, especially in males ${ }^{(58)}$. In a cross-sectional study with adolescents, leptin was inversely related to testosterone in boys and positively related to estradiol in girls ${ }^{(59)}$. In this sense, an in vitro study verified that testosterone can suppress 
leptin expression, even at the mRNA level ${ }^{(60)}$, confirming the previous finding. Therefore, in the present study, we believe that changes in androgens during puberty may have influenced adipokine concentrations in adolescents.

To the best of our knowledge, there are still no studies on adiponectin and leptin reference values for obese adolescents. Therefore, we suggest the advancement of research in this subject.

In relation to dietary intake and lung function, we observed that obese asthmatics had lower values of lung function and higher consumption of lipids, polyunsaturated fats and cholesterol compared with non-asthmatics in all evaluation periods. However, it is interesting to note that after a 6-month intervention, FVC, FEV1 and PEF in obese asthmatic patients were close to the baseline values of the obese non-asthmatic group. Furthermore, after the interdisciplinary intervention of 1 year, both groups showed a reduction in the consumption of lipids, cholesterol, saturated and polyunsaturated fats, $\mathrm{Na}$ and had increased lung function associated with clinical improvement of asthma symptoms, demonstrating the effectiveness of this treatment strategy and suggesting a relationship between nutrient intake and lung function.

In this intervention, cholesterol intake was a predictor of lung function. The new Dietary Guidelines for Americans does not establish a maximum value for cholesterol intake, justifying that there is no direct relationship between dietary cholesterol and its levels in blood ${ }^{(61)}$. However, a recent systematic review ${ }^{(62)}$ and meta-analysis ${ }^{(63)}$ showed that only a consumption of high cholesterol can increase serum cholesterol by up to $5 \%$. Some studies have found it difficult to verify this result because of confounding factors, such as body mass, which has an influence on cholesterol metabolism ${ }^{(56,63)}$. Obese people appear to absorb more cholesterol compared with lean individuals ${ }^{(64)}$. Therefore, studies on the consumption and metabolism of cholesterol in different clinical settings, such as obesity and asthma, are timely.

From this point of view, the literature demonstrates a positive relationship between serum concentrations of cholesterol and asthma severity ${ }^{(65,66)}$. However, studies were conducted mainly with children and adults, and only serum cholesterol was investigated. Obese asthmatics between 10 and 14 years of age showed higher cholesterol levels compared with obese children without asthma. Similarly, in Indian adults, a positive relationship was observed between serum cholesterol and the risk of asthma, regardless of age, sex, BMI and adipokines. Cholesterol is the main lipid fraction of the surfactant, a substance that helps reduce the surface tension of the pulmonary alveolar and respiratory efforts. In this regard, it is believed that excess cholesterol in the blood can change surfactant composition as well as its function, leading to lung collapse $\mathrm{e}^{(67,68)}$. Therefore, the finding of an inverse relationship between cholesterol consumption and FEV1:FVC in the present study suggests the importance of reducing cholesterol consumption to improve lung function and asthma control.

The pathophysiology of asthma-obesity is complex, and its mechanisms are being elucidated, but our study strengthens the hypothesis that it is impossible for only one pathway to be responsible for the disease. Thus, a lack of healthy lifestyle coupled with an obesogenic diet, characterised by high cholesterol and refined carbohydrate intake as well as low consumption of fibres, vitamins and minerals, has been associated with an increased risk of asthma ${ }^{(14,69)}$.

The total energy value of the diet was a predictor of reduced FVC, and carbohydrate consumption was a negative predictor of the FEV1:FVC ratio. These findings corroborate previous studies showing that meals with a high carbohydrate content increase the expression of $\mathrm{NF}$ - $\mathrm{B}^{(70)}$, and energy restriction in the diet contributes to reducing the concentrations of TNF- $\alpha$ and carbonyl proteins, nitrotyrosine and 8-isopropanol, which are markers of oxidative stress, and may influence airway inflammation associated with asthma symptoms ${ }^{(71)}$.

In our study, adolescents in both groups consumed Ca below reference values ${ }^{(72)}$. Moreover, there was a positive association between $\mathrm{Ca}$ intake and lung function in obese adolescents. These findings suggest a possible relationship between Ca deficiency and asthma symptoms and assumes that an increased intake of this mineral may improve lung function. In the literature, there are few studies on micronutrient intake in asthmatic patients. However, a previous study has found low Ca concentrations in asthmatic children $^{(73)}$. It is known that $\mathrm{Ca}$ influences homeostasis and the contraction of pulmonary smooth muscles ${ }^{(37)}$, but the specific mechanisms of these events are yet to be elucidated.

Regarding fibre consumption, both groups reported levels lower than the reference values ${ }^{(72)}$. In fact, we found, for the first time, a proportional relationship between fibre intake and airway obstruction in obese adolescents. To our knowledge, there are no studies with adolescents; however, our findings corroborate a population study conducted with adults, in which a proportional association was found between fibre intake and lung function ${ }^{(74)}$. A reduction in pulmonary inflammation may be one of the mechanisms by which dietary fibres increase airflow. It has already been observed that fibre consumption was inversely associated with airway eosinophilia ${ }^{(20)}$ and a reduction of neutrophils, macrophages, lymphocytes and nitric oxide in the respiratory system ${ }^{(16)}$. Further research is needed to investigate the influence of fibre intake on the specific phenotype, non-atopic asthma, obesity and in different audiences. Furthermore, it is known that there are soluble and insoluble fibres. It is possible that both types are important in asthma or one of them may have more benefits than the other; therefore, further studies are necessary.

In foods that are fibre sources, we also found antioxidant nutrients such as vitamin $\mathrm{A}$, which can improve the immune system and reduce asthma symptoms ${ }^{(75)}$. Vitamin A is absorbed in the human body in the form of retinoic acid, which increases the expression of IL-4, an anti-inflammatory cytokine ${ }^{(76)}$. However, a meta-analysis has found that vitamin A dietary intake was lower in asthmatic patients compared with non-asthmatic ones and in individuals with severe asthma compared with those with mild asthma. Additionally, a low vitamin A intake was positively associated with wheezing ${ }^{(77)}$. Therefore, these findings corroborate our investigation, in which a lower intake of vitamin A was a predictor of lower values of FEV1:FVC and PEF, which are considered inferior airway obstruction markers ${ }^{(37)}$.

One of the limitations of the present study is the absence of eutrophic asthmatic control or untreated obese to check for placebo effect. However, strengths include (1) evaluation of 
biochemical markers (adiponectin, leptin); (2) analysis of fat and lean mass percentage, visceral and subcutaneous fat in addition to BMI; and (3) investigation of macro- and micronutrients.

We realise the importance of the interdisciplinary treatment in asthma-obesity in order to improve nutrition, body composition and lung function in obese adolescents. However, further studies are needed to more accurately explain the mechanisms linking dietary intake to the pathophysiology of obesity-asthma, so that dietary management aimed at the prevention and treatment of obesity-asthma may be possible in the future. We propose that efforts be made to investigate: (1) reference values of leptin and adiponectin levels in obese adolescents; (2) consumption of micronutrients and their serum concentrations in adolescents, especially obese asthmatics; (3) role of Ca in homeostasis and contraction of the pulmonary muscle, and (4) effects of cholesterol, saturated fats and fibre consumption in the intestinal microbiota of obese asthmatic adolescents and their influence on adipokine production and secretion and pulmonary inflammation.

\section{Acknowledgements}

The authors thank the Federal University of Goiás Nutrition and Health Graduation Programme (Programa de Pós-Graduação em Nutrição e Saúde da Universidade Federal de Goiás PPGNUT) and the Federal University of São Paulo Obesity Studies Group (Grupo de Estudos em Obesidade da Universidade Federal de São Paulo - GEO/UNIFESP). A very special thank you to the adolescents and their parents.

The study did not receive any specific funding from any financing agency, commercial or non-profit sectors.

There were no conflicts of interest.

\section{Supplementary material}

For supplementary material/s referred to in this article, please visit https://doi.org/10.1017/S0007114519001739

\section{References}

1. Dobbs R, Sawers C, Thompson F, et al. (2014) The Obesity Crisis. New York: McKinsey Global Institute.

2. Global Initiative for Asthma - GINA (2017) Global Strategy for Asthma Management and Prevention - Online Appendix 2017 Update. London: GINA.

3. Rasmussen F \& Hancox RJ (2014) Mechanisms of obesity in asthma. Curr Opin Allergy Clin Immunol 14, 35-43.

4. Lang JE (2012) Obesity, nutrition, and asthma in children. Pediatr Allergy Immunol Pulmonol 25, 64-75.

5. Ford ES (2005) The epidemiology of obesity and asthma. J Allergy Clin Immunol 115, 897-909.

6. Beuther DA \& Sutherland ER (2007) Overweight, obesity, and incident asthma: a meta-analysis of prospective epidemiologic studies. Am J Resp Crit Care Med 175, 661-666.

7. Brumpton B, Langhammer A, Romundstad P, et al. (2013) General and abdominal obesity and incident asthma in adults: the HUNT study. Eur Respir J 41, 323-339.

8. Papoutsakis C, Chondronikola M, Antonogeorgos G, et al. (2015) Associations between central obesity and asthma in children and adolescents: a case-control study. J Asthma 52, 128-134.
9. Azizpour Y, Delpishe A, Montazeri Z, et al. (2018) Effect of childhood BMI on asthma: a systematic review and metaanalysis of case-control studies. BMC Pediatr 18, 143.

10. Hayden ML, Stoloff SW, Colice GL, et al. (2012) Exerciseinduced bronchospasm: a case study in a nonasthmatic patient. J Am Acad Nurse Pract 24, 19-23.

11. Tassoudis V, Ieropoulos H, Karanikolas M, et al. (2016) Bronchospasm in obese patients undergoing elective laparoscopic surgery under general anesthesia. Springerplus $\mathbf{5}, 435$.

12. Mohanan S, Tapp H, McWilliams A, et al. (2014) Obesity and asthma: pathophysiology and implications for diagnosis and management in primary care. Exp Biol Med 239, $1531-1540$.

13. Dixon AE \& Poynter ME (2016) Mechanisms of asthma in obesity pleiotropic aspects of obesity produce distinct asthma phenotypes. Am J Respir Cell Mol Biol 54, 601-608.

14. Ellwood P, Asher MI, Garcia-Marcos L, et al. (2013) Do fast foods cause asthma, rhinoconjunctivitis and eczema? Global findings from the International Study of Asthma and Allergies in Childhood (ISAAC) Phase Three Thorax 68, 351-360.

15. Harte AL, Varma MC, Tripathi G, et al. (2012) High fat intake leads to acute postprandial exposure to circulating endotoxin in type 2 diabetic subjects. Diabetes Care 35, 375-382.

16. Halns I, Baines KJ, Berthon BS, et al. (2017) Soluble fibre meal challenge reduces airway inflammation and expression of GPR43 and GPR41 in asthma. Nutrients 9, E57.

17. Shore SA \& Cho Y (2016) Obesity and asthma: microbiomemetabolome interactions. Am J Respir Crit Care Med 54, 609-617.

18. Sideleva O, Black K \& Dixon AE (2013) Effects of obesity and weight loss on airway physiology and inflammation in asthma. Pulm Pharmacol Ther 26, 455-458.

19. Han YY, Forno E, Holguin F, et al. (2015) Diet and asthma: an update. Curr Opin Allergy Clin Immunol 15, 369-374.

20. Berthon BS, Macdonald-Wicks LK, Gibson PG, et al. (2013) Investigation of the association between dietary intake, disease severity and airway inflammation in asthma. Respirology 18, 447-454.

21. Maslowski KM, Vieira AT, Ng A, et al. (2009) Regulation of inflammatory responses by gut microbiota and chemoattractant receptor GPR43. Nature 461, 1282-1286.

22. Boulet LP (2013) Asthma and obesity. Clin Exp Allergy 43, 8-21.

23. Gruchala-Niedoszytko M, Malgorzewicz S, Niedoszytko M, et al. (2013) The influence of obesity on inflammation and clinical symptoms in asthma. Adv Med Sci 58, 15-21.

24. Scott HA, Jensen ME \& Wood LG (2014) Dietary interventions in asthma. Curr Pharm Des 20, 1003-1010.

25. Lee H, Lee S \& Choue R (2013) Obesity, inflammation and diet. Pediatric Gastroenterol Hepatol Nutr 16, 143-152.

26. Luna-Pech JA, Torres-Mendoza BM, Luna-Pech, JA, et al. (2014) Normocaloric diet improves asthma-related quality of life in obese pubertal adolescents. Int Arch Allergy Immonol 163 , 252-258.

27. Da Silva PL, De Mello MT, Cheik NC, et al. (2012) Interdisciplinary therapy improves biomarkers profile and lung function in obese asthmatic adolescents. Pediatr Pulmonol $\mathbf{4 7}$, 8-17.

28. Sociedade Brasileira de Pneumologia e Tisologia (2012) Diretrizes da Sociedade Brasileira de Pneumologia e Tisologia para o manejo da asma (Guidelines of the Brazilian Society of Pulmonology and Asthma for asthma management). J Bras Pneumol 38, Suppl. 1, S1-S46.

29. Dias J \& Farzan S (2014) Clinical implications of obese-asthma phenotypes. Immunol Allergy Clin North Am 34, 739-751. 
30. Liu X, Lin R, Zhao B, et al. (2016) Correlation between oxidative stress and the NF- $\mathrm{KB}$ signaling pathway in the pulmonary tissues of obese asthmatic mice. Mol Med Rep 13, 1127-1134.

31. Marshall WA \& Tanner JM (1969) Variations in pattern of pubertal changes in girls. Arch Dis Child 44, 291-303.

32. Marshall WA \& Tanner J M (1970) Variations in pattern of pubertal changes in boys. Arch of Dis Child 45, 13-23.

33. Kuczmarski RJ, Ogden CL, Guo SS, et al. (2002) 2000 CDC growth charts for the United States: methods and development. National Center for Health Statistics. Vital Health Stat 11, $1-190$.

34. Lohman TG, Roche AF \& Martorrel R (1991) Anthropometric: Standardization Reference Manual, abbreviated ed., p. 30 [R Martorrel, editor]. Champaign, IL: Human Kinetic Books.

35. Ribeiro-Filho FF, Faria AN, Azjen S, et al. (2003) Methods of estimation of visceral fat: advantages of ultrasonography. Obes Res 11, 1488-1494.

36. American Thoracic Society (2014) Guidelines for assessing and managing asthma risk at work, school, and recreation. $A m J$ Respir Crit Care Med 169, 873-881.

37. Sociedade Brasileira de Pneumologia e Tisiologia (2002) Diretrizes para teste de função pulmonar (Pulmonary function test guidelines). J Bras Pneumol 28, 1-12.

38. Knudson RJ, Lebowitz MD, Holberg CJ, et al. (1983) Changes in the normal maximal expiratory flow-volume curve with growth and aging. Am Rev Respir Dis 127, 725-734.

39. Sociedade Brasileira de Pneumologia e Tisiologia (2006) IV Diretrizes Brasileiras para Manejo da Asma (IV Brazilian Guidelines for Asthma Management). J Bras Pneumol 32, 447-474.

40. Bateman ED, Hurd SS., Barnes PJ, et al. (2008) Global Strategy for Asthma Management and Prevention: GINA executive summary. Eur Respir J 31, 143-178.

41. Anção MS, Cuppari L, Tudisco ES, et al. (2002) NutWin Programa de Apoio a Nutrição Versão 2.5 (Nutrition Support Program Version 2.5) [software]. São Paulo: Centro de Informática em Saúde, Universidade Federal de São Paulo/ Escola Paulista de Medicina.

42. National Research Council (2000) Dietary Reference Intakes (DRI): Applications in Dietary Assessment. Washington, DC: National Academies Press.

43. Corgosinho FC, Elia CA, Tufik S, et al. (2015) Beneficial effects of a multifaceted 1-year lifestyle intervention on metabolic abnormalities in obese adolescents with and without sleep-disordered breathing. Metab Syndr Relat Disord 13, 110-118.

44. Donnelly JE, Blair SN, Jakicic JM, et al. (2009) American College of Sports Medicine. American College of Sports Medicine Position Stand. Appropriate physical activity intervention strategies for weight loss and prevention of weight regain for adults. Med Sci Sports Exerc 41, 459-471.

45. Craig CL, Marshall AL, Sjöström M, et al. (2003) International Physical Activity Questionnaire: 12-country reliability and validity. Med Sci Sports Exerc 35, 1381-1395.

46. Rosner B (2011) Fundamentals of biostatistics. In Descriptive Statistics, 7 th ed., pp. 5-39. Stamford, CT: Cengage Learning.

47. Mukaka MM (2012) A guide to appropriate use of correlation coeficiente in medical reserch. Malawi Med J 24, 69-71.

48. Egan KB, Ettinger AS, Dewan AT, et al. (2015) Longitudinal associations between asthma and general and abdominal weight status among Norwegian adolescents and young adults: the HUNT Study. Pediatr Obes 10, 345-352.

49. Juel CT \& Urlrik CR (2013) Obesity and asthma impacto n severity, asthma control, and response to therapy. Respir Care 58, 867-873.
50. Ahmadizar F, Uijverberg JH, Arets HCM, et al. (2016) Childhood obesity in relation to poor asthma control and exacerbation: a meta-analysis. Eur Respir J 48, 1063-1073.

51. Huang F, Del-Rio BE, Torres-Alcantara S, et al. (2017) Adipokines, asymmetrical dimethylarginine, and pulmonar function in adolescentes with asthma and obesity. $J$ Asthma 54, 153-161.

52. Jensen ME, Gibson PG, Collins CE, et al. (2013) Diet-induced weight loss in obese children with asthma: a randomized controlled trial. Clin Exp Allergy 43, 775-184.

53. Campos RMDS, Masquio DCL, Corgosinho FC, et al. (2018) Relationship between adiponectin and leptin on osteocalcin in obese adolescents during weight loss therapy. Arch Endocrinol Metab 62, 275-284.

54. Lausten-Thomsen U, Christiansen M, Louise Hedley P, et al. (2016) Reference values for serum leptin in healthy non-obese children and adolescents. Scand J Clin Lab Invest 76, 561-567.

55. Elloumi M, Ben-Ounis O, Makni E, et al. (2009) Effect of individualized weight-loss programmes on adiponectin, leptin and resistin levels in obese adolescent boys. Acta Paediatr 98, 1487-1493.

56. Andersen CJ (2018) Impact of dietary cholesterol on the pathophysiology of infectious and autoimmune disease. Nutrients 10, E764.

57. Yarrow JF, Beggs LA, Conover CF, et al. (2012) Influence of androgens on circulating adiponectin in male and female rodents. PLOS ONE 7, e47315.

58. Bottner A, Kratzsch J, Muller G, et al. (2004) Gender differences of adiponectin levels develop during the progression of puberty and are related to serum androgen levels. J Clin Endocrinol Metab 89, 4053-4061.

59. Xi H, Zhang L, Guo Z, et al. (2011) Serum leptin concentration and its effect on puberty in Naqu Tibetan adolescents. J Physiol Anthropol 30, 111-117.

60. Wabitsch M, Blum WF, Muche R, et al. (1997) Contribution of androgens to the gender difference in leptin production in obese children and adolescents. Clin Invest 100, 808-813.

61. Department of Agriculture and U.S. Department of Health and Human Services (2015) Dietary Guidelines for Americans 2015-2020, 8th ed. Washington, DC: Office of Disease Prevention and Health Promotion.

62. Grundy SM (2016) Does dietary cholesterol matter? Curr Atheroscler 18, 68.

63. Berger S, Ramon G, Vishwanathan R, et al. (2015) Dietary cholesterol and cardiovascular disease: a systematic review and meta-analysis. Am J Clin Nutr 102, 276-294.

64. Miettinen TA \& Gylling H (2000) Cholesterol absorption efficiency and sterol metabolism in obesity. Atherosclerosis $\mathbf{1 5 3}$, 241-248.

65. Chen YC, Tung KY, Tsai CH, et al. (2013) Lipid profiles in children with and without asthma: interaction of asthma and obesity on hyperlipidemia. Diabetol Metab Syndr 7, 20-25.

66. Ramaraju K, Krishnamurthy S, Maamidi S, et al. (2013) Is sérum cholesterol a risk factor for asthma? Lug India 30, 295-301.

67. Veldauizen R, Nag K, Orgeig S, et al. (1998) The role of lipids in pulmonar surfactante. Biochim Biophys Acta 1408, 90-108.

68. Fessler MB (2017) A new frontier in immunometabolism: cholesterol in lug health and disease. Ann Am Thorac Soc 14, Suppl. 5, S399-S405.

69. Wood LG (2017) Diet, obesity and asthma. Ann Am Thorac Soc 14, Suppl. 5, S332-S338.

70. Patel C, Ghanim H, Ravishankar S, et al. (2007) Geration of prolonged reactive oxygen species and activation of nuclear factor-kB a high-fat, high-carbohydrate meal in the obese. J Clin Endocrinol Metab 92, 4476-4479. 
71. Johnson JB, Summer W \& Cutler RG (2007) Alterate day calorie restriction improves clinical findings and reduces markers of oxidative stress and inflammation in overweight adults with moderate asthma. Free Radic Biol Med $\mathbf{4 2}$, 665-675.

72. Intitute of Medicine (2005) Dietary Reference Intakes for Energy, Carbohydrate, Fiber, Fat, Fatty Acids, Cholesterol, Protein, and Amino Acids. Washington, DC: National Academies Press.

73. Hijazi N, Abalkhail B \& Seaton A (2000) Diet and childhood asthma in a society in transition: a study in urban and rural Saudi Arabia. Thorax 55, 775-779.
74. Hanson C, Lyden E, Rennard S, et al. (2016) The relationship between dietary fiber intake and lung function in the National Health and Nutrition Examination Surveys. Ann Am Thorac Soc 13, 643-650.

75. Barranco P, Delgado J, Gallego LT, et al. (2012) Asthma, obesidade y dieta (Asthma, obesity and diet). Nutr Hosp 27, 138-145.

76. Han YY, Blatter J, Brehm JM, et al. (2013) Diet and asthma: vitamins and methyl donors. Lancet Respir Med 1, 813-822.

77. Allen S, Britton JR \& Leonardi-Bee JÁ (2009) Association between antioxidant vitamins and asthma outcome measures: systematic reviev and meta-analysis. Thorax 64, 610-619. 